\title{
APPLICATION OF GRAPHENE OXIDE ON APTAMER-BASED BIOSENSOR DEVELOPMENT FOR AUTHENTICATION OF GELATIN
}

\author{
HARI WIDADA ${ }^{1,2}$, ABDUL ROHMAN ${ }^{1 *}$, RIRIS ISTIGHFARI JENIE ${ }^{1},{\text { SISMINDARI }{ }^{1 * *}}^{*}$
}

${ }^{1}$ Faculty of Pharmacy, Universitas Gadjah Mada, Yogyakarta, Indonesia 55281, ${ }^{2}$ Faculty of Medical and Health Sciences, Universitas Muhammadiyah Yogyakarta, Yogyakarta 55183, Indonesia, ${ }^{1 *}$ School of Pharmacy, Faculty of Medical and Health Sciences, Universitas Muhammadiyah Yogyakarta, Indonesia 55183

Email: abdulrohmanugm@gmail.com

Received: 03 Dec 2018, Revised and Accepted: 30 Jan 2019

\section{ABSTRACT}

Objective: The objective of this study was to perform aptamer selection using systematic evolution of ligands by exponential enrichment (SELEX) method which assisted by graphene oxide against target of porcine gelatin (non-halal gelatin).

Methods: The aptamer selection was carried out using SELEX method without target immobilization. Selection of aptamer capable of binding porcine gelatin by applying grafen oxide (GO) was known as GO-SELEX. The selection process was initially carried out by incubation of singlestranded DNA (ssDNA) libraries targeting on porcine gelatin with the addition of graphene oxide. The selected ssDNA was then purified by several stages namely; symmetric PCR amplification, purification of products with DNA purification kits, asymmetric PCR amplification, and continued purification of DNA with native PAGE. The analysis of each stage was done by agarose gel electrophoresis.

Results: the results showed that aptamer targeting porcine DNA could be selected. This was indicated by the results of DNA analysis using native polyacrylamide gel electrophoresis (PAGE) in which sharp separation band with a base length equivalent to the marker of the ssDNA library (about 80 base pair) was obtained.

Conclusion: Aptamer targeting on porcine gelatin has been successfully developed using GO-SELEX method. GO can increase selectivity in developing aptamer which will be used as a biosensor to detect porcine gelatin. The method could be proposed as a standard of apatamer based method for porcine gelatin detection on halal products authentication.

Keywords: Graphene oxide, Aptamer, Porcine gelatin, GO-SELEX

(C) 2019 The Authors. Published by Innovare Academic Sciences Pvt Ltd. This is an open access article under the CC BY license (http://creativecommons.org/licenses/by/4.0/) DOI: http://dx.doi.org/10.22159/ijap.2019v11i2.31122

\section{INTRODUCTION}

Gelatine, obtained from partial hydrolysis of collagen of bones and skins of pig and cattle is commonly used in several industries including in food, pharmaceuticals, and cosmetics. In pharmaceutical application, gelatine is commonly exploited for preparing either hard or soft capsule shells [1] and components in pharmaceutical formulation $[2,3]$. The encapsulated active pharmaceutical ingredient can be protected from moisture, heat or other extreme conditions in order to enhance its stability. It is reported that the main sources of gelatin used in pharmaceutical industries are cattle bones accounting of $23.1 \%$, bovine skin accounting of $9.4 \%$ and pigskin accounting of $46 \%$. Currently, gelatin is also prepared from several types of fish [4]. Gelatine is mainly constituted from amino acids which are essential for human body [5].

The moslem community, especially the follower of school of thougth (madzhab) syafi'i is not allowed to consume food and pharmaceutical products containing porcine gelatin [6], as a consequence, some methods for identification of gelatin sources has been extensively proposed and applied. Physico-chemical methods based on spectroscopic such as fourier transform infrared spectroscopy (FTIR) [7] and chromatographic like liquid chromatography [8], mass spectrometry [9] have been widely applied for differentiation among gelatines, however, this method is lack in selectivity, thus molecular biology-based methods were currently used for gelatin analysis.

DNA-based methods especially polymerase chain reaction is an excellent method to be applied for identification of gelatin sources. Real-time PCR [10], Restriction Fragment Length Polymorphism (RFLP) [11], PCR multiplex [12], and species-specific PCR [13] have been used for identification of DNA from pig species (porcine DNA). Aptamer, a short chain oligonucleotide of RNA or single-stranded DNA (ssDNA), can bind selectively ligand with high specificity [14]. Aptamer can bind several target molecules including DNA, peptide, nucleotide and other molecules with low molecular weight [15].
Aptamer could be obtained from multiple selection in vitro secara using the method known as SELEX (Systematic Evolution of Ligands by Exponential Enrichment). SELEX comprised 4 processes, namely binding, elution, amplification and separation. SELEX has emerged as a powerful method for isolation of nucleic acid aptamer with high sensitivity and selectivity and ease in its production [16].

Nanomaterial-based on graphene oxide has been widely used for making functional biosystem integrated with nucleic acids, peptides, protein and even with cells [16]. The capability of ssDNA to be absorbed on graphene and the nature difference between ssDNA and dsDNA in its retention has led the development of biosensor [17]. This study was aimed to perform a selection of aptamer using SELEX method assisted by graphene oxide (GOSELEX) against analyte target (porcine gelatin). Aptamer obtained was used as biosensor using nanoparticle platform for detecting porcine (Sus scrofa domestica) DNA.

\section{MATERIALS AND METHODS}

This research was intended to perform aptamer selection using SELEX method modified with the use of graphene oxide (G0). The selection was carried out by a series of processes and separation of aptamer using Sigma/Sartorius 3-18K andinkubator (Memmert In55). The separated aptamer was amplified using Bio-Rad T-100 ${ }^{\mathrm{TM}}$ Thermal Cycler, analyzed using electrophoresis gel agarose and visualized with UV illuminator.

\section{Primer design}

Primer ssDNA libraries were designed based on gen $C y t-b$ babi with accession number: AF039170 [18]:

Forward primer: 5'-GCCTAAATCTCCСCTCAATGGTA-3'.

Reverse primer: 5'-ATGAAAGAGGCAAATAGATTTTCG-3'.

ssDNA library was synthesized randomly with the end of forward primer and its complement reverse primer as: 


\section{5'-GCCTAAATCTCCCCTCAATGGTA-N40-} CGAAAATCTATTTGCCTCTT-TCAT-3'.

The designed primer and ssDNA was synthesized in Integrated DNA Technologies (IDT) through PT. Genetika Science, Jakarta, Indonesia. PCR using Master Mix KAPA Taq Ready Mix 1x (KAPA Biosystem) andMyTaq ${ }^{\mathrm{TM}}$ HS Red Mix Bioline (Bioline Reagents Ltd., UK) was employed. The purification of PCR products was performed using Illustra GFX PCR DNA and Gel Band Purification Kit (GE Healthcare, USA) and DNA Clean and Concentrator 5 (Zymo Research).

\section{Application of grapheme oxide in aptamer selection}

The library of ssDNA was reconstituted with binding buffer $\mathrm{pH} 7.4$ and heated at $94^{\circ} \mathrm{C}$ for $5 \mathrm{~min}$. The mixture was cooled in ice bath for $15 \mathrm{~min}$ and allowed to stand at $25^{\circ} \mathrm{C}$ for $10 \mathrm{~min}$. Selection cycle I: in the microtube, 1, 2, $3 \mathrm{nmol}$ ssDNA incubated with 5, 10, $15 \mathrm{mg}$ of porcine gelatin in $400,300,200 \mu$ l binding buffer was added with etanol \%, stirred for 2 hour at the temperature of $25^{\circ} \mathrm{C}$. The mixture was then added with $100,200,300 \mu \mathrm{l}$ graphene oxide $(2 \mathrm{mg} / \mathrm{ml})$ into mixture, incubated at $25^{\circ} \mathrm{C}$ for $40 \mathrm{~min}$ (mass ratio of graphene oxide/ssDNA = 40: 1). The mixture was centrifuged at $13000 \mathrm{rpm}$ for $10 \mathrm{~min}$. The supernatant containing ssDNA binded on gelatin was pooled, while deposite (ssDNA which was not binded and adsorbed on graphene oxide) was removed [19].

\section{Purification of an aptamer using asymmetric PCR}

The selection products were purified using asymmetric PCR which was started by amplification using PCR according to [20] with slight modification. The amplification step was: initial denaturation of 95 ${ }^{\circ} \mathrm{C}$ for $1 \mathrm{~min}$, denaturation at $95{ }^{\circ} \mathrm{C}$ for $15 \mathrm{sec}$, annealing at $49.05^{\circ} \mathrm{C}$ (from annealing temperature optimization) for $15 \mathrm{sec}$, extension at $72{ }^{\circ} \mathrm{C}$ for $10 \mathrm{sec}$, with PCR cycle of $25-35$, and final extension at $72{ }^{\circ} \mathrm{C}$ for 5 min. PCR products were purified using purification kits of DNA Clean and Concentrator ${ }^{\mathrm{TM}} 5$ from Zymo Research. The purified DNA was then amplified using asymmetric PCR with primer ration of: $10 / 4,12 / 2,14 / 0$, followed with the ratio of forward/reverse primers of: $5 / 0,10 / 0,15 / 0,20 / 0$. The products were analyzed using gel agarose $3 \%$ in buffer TAE ( $40 \mathrm{nMTris}$-acetate and $1 \mathrm{mmol}$ EDTA, pH 8.0) containing $0.5 \mathrm{ug} / \mathrm{ml}$ ethidium bromide and visuliazed with UV Transilluminator.

\section{Purification of ssDNA gel}

PCR product was precipitated with absolute ethanol until final volume of $20 \mathrm{uL}$. The product was purified with $10 \%$ native polyacrylamide gel electrophoresis, TBE buffer $(89 \mathrm{mmol}$ tris-Boric, $2 \mathrm{mmol}$ EDTA, $\mathrm{pH}$ 8.3), and was stained with $0.5 \mu \mathrm{g} / \mathrm{ml}$ ethidium bromida in $1 \mathrm{x}$ bufer TBE for 7 menit. ssDNA band was purified using crush and soakmethod. Band containing ssdNA was cut using the sterile cutter and was then placed into Effendorf. Gel was destroyed using steril pipette tip followed by addition of $400 \mu$ l eluting buffer (1 M Na-asetat; $0.01 \mathrm{M}$ EDTA). The sample was incubated at $37{ }^{\circ} \mathrm{C}$ for 6-8 $\mathrm{h}$ with shaking at $900 \mathrm{rpm}$. The gel particles were precipitated with centrifugation for 2 min and the supernatant was precipitated with ethanol with final volume of $20 \mu \mathrm{l}$ [21].

\section{RESULTS AND DISCUSSION}

The development of non-halal component detection becomes important to provide comfort for the ummah. Methods or detection tools that have high accuracy and sensitivity, inexpensive, and within easy reach will greatly assist the monitoring process. One of the potential methods to be applied in a non-halal analysis is based on a biosensor using aptamer, a short-stranded oligonucleotide in the form of RNA or single-stranded DNA (ssDNA) that can be selectively bound with ligands or target proteins with high affinity and specificity [22]. Graphene and graphene oxide (GO) are fairly wide-ranging two-dimensional nanoparticles used as platforms in biosensors. The difference in the affinity of graphene oxide to ssDNA and dsDNA is then adopted in the test to observe DNA.

The process was started by designing and synthesizing sequence library of nucleic acids (DNA/RNA) randomly, which were normally composed of aptamer with variation until $\sim 10^{15}$ capable of binding with analyte target (porcine gelatin) specifically. To obtain a variety ssDNA library, the bases of A: G: C: T with ratio of 1.5: 1.25: 1.15: 1.0 were used. The library diversity was determined by chain length from ssDNA randomly designed, and in this study, the sequence with 40 bases was randomly designed. This 40 sequence, in turn, resulted in huge number of new sequences. The high library diversity could find aptamer which can be selected to bind with porcine gelatin.

\section{Application of graphene oxide in aptamer selection (GO-SELEX)}

In the first selection, ssDNA with concentrations of $1,2,3 \mathrm{nmol}$ in microtube $1.5 \mathrm{ml}$ was used. The mixture was incubated with $5,10,15$ $\mathrm{mg}$ porcine gelatin with the addition of binding buffer and ethanol $1 \%$. In order to select aptamer capable of binding with porcine gelatin, the mixture was incubated for $2 \mathrm{~h}$ at $25^{\circ} \mathrm{C}$. The separation of ssDNA which was not bound to analyte target was carried out by addition of graphene oxide (GO). The binding capacity of GO toward ssDNA was enhanced by incubation at $25^{\circ} \mathrm{C}$ for $40 \mathrm{~min}$. ssDNA sequence which do not bind porcine gelatin could be adsorbed by GO via $\pi-\pi$ interactions among bases of ssDNA with the surface of GO. In order to separate ssDNA bound and not bound with porcine gelatin, the centrifugation of mixture at $13000 \mathrm{rpm}$ for $10 \mathrm{~min}$ was applied. The supernatant was ssDNA binding porcine gelatin, while precipitate was ssDNA which not bound and adsorbed by GO. The DNA profile could be separated and was analyzed by electrophoresis gel agarose $3 \%$ was shown in fig. 1 .
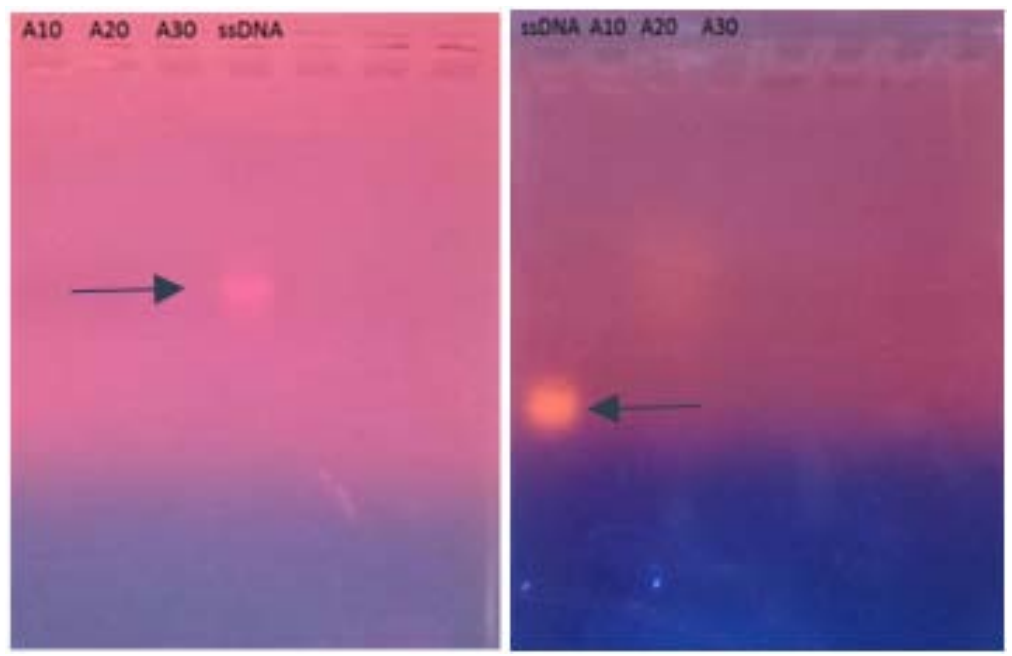

Fig. 1: The electrophoresis of DNA on gel agarose; (a) using agarose $3 \%$, (b) using agarose $0.8 \%$. The arrow ( $\longrightarrow$ ) indicated band of ssDNA library as control 
The DNA as result of selection was analyzed using electrophoresis gel agarose with 2 different agarose concentrations, namely $0.8 \%$ and $3.0 \%$ using buffer TAE $1 \mathrm{x}$. The ssDNA library was used as marker to investigate whether products have the same length with the used library. The result showed that isolate has not appeared band clearly yet. This is due to low concentration of DNA target so that the isolate was continued with PCR amplification. To amplify ssDNA, symmetrical PCR was used, i.e. amplification of ssDNA target and its complementary DNA using forward and reverse primers with the same ratio. The results of symmetrical PCR was then purified using DNA purification kits using protocol set in the manufacture procedure. The purified products were then purified again using asymmetrical PCR, using primer ratio of $x / 0$, i.e. forward primer was varied while reverse primer was made constant. The objective of ssDNA purification using asymmetrical PCR was to amplify template sequence which complements with ssDNA target.

The results of asymmetrical PCR using master mix KAPA Taq Ready Mix were then analyzed using electrophoresis gel agarose $3 \%$ as shown in fig. 2 . The result showed that all primer ratios of $5 / 1,10 / 1$ and $20 / 1$ could obtain amplification products toward DNA target. This was indicated by band which parallel to marker band (ssDNA library). The next step was an amplification of ssDNA with primer ratio of $\mathrm{x} / 0$ (no reverse primer used during PCR analysis) so that the amplification only occurred in DNA template. The results could be seen in fig. 3.

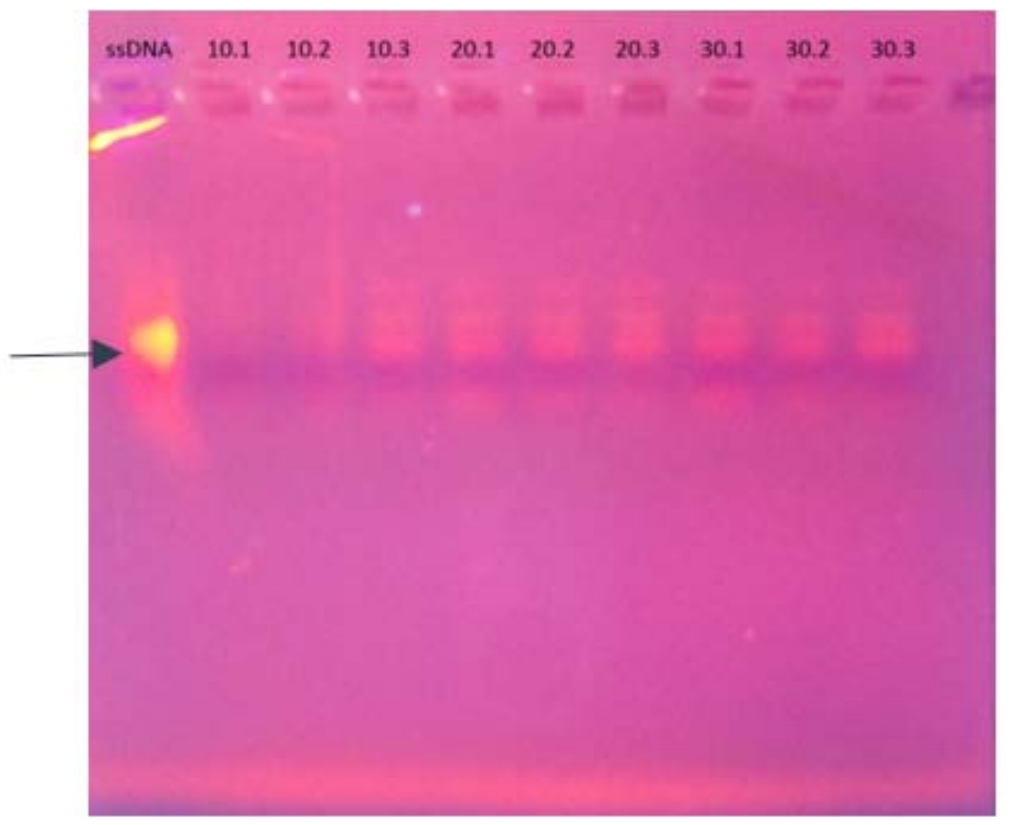

Fig. 2: Electrophoresis gel agarose $3 \%$ of PCR products using primer ratio $x / 1$. The ssDNA was marker. The arrow $(\longrightarrow)$ indicated amplification band

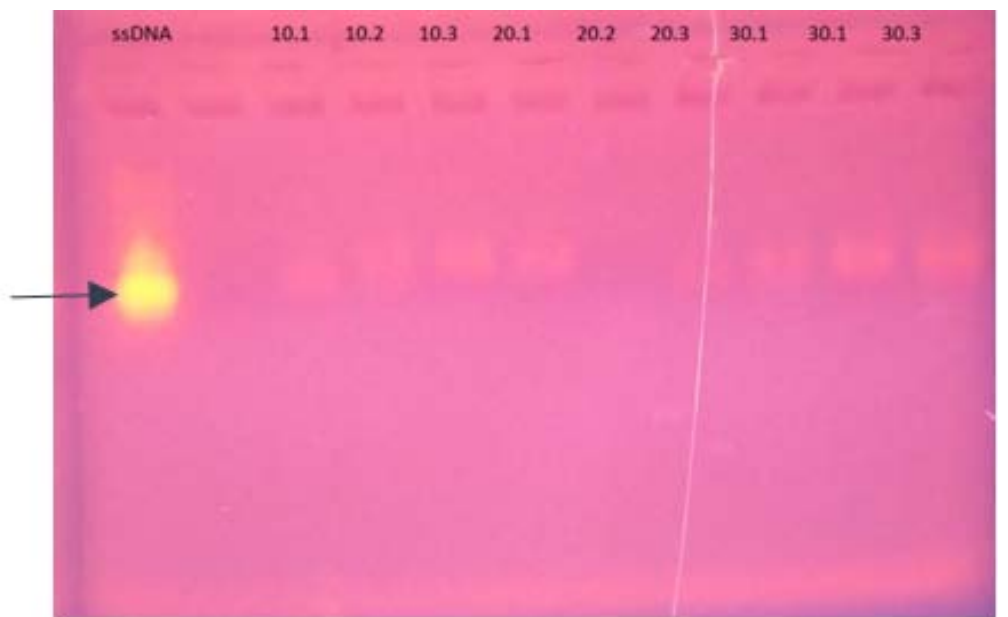

Fig. 3: Electrophoresis gel agarose $3 \%$ of PCR products using primer ratio x/0; 5/0; 10/0; 20/0. The arrow $(\longrightarrow)$ indicated amplification band

Asymmetrical PCR with a decreased ratio of reverse primer (fig. 4) showed the different profiles of electrophoresis results. Reverse primer with ratio of $14 / 0$ could yield higher amplification products, as indicated by clearer separation band under UV illuminator. In addition, using asymmetrical PCR with primer ratio x/o (5/0, 10/0, $15 / 0$, and $20 / 0$ ), the amplification products were shown in fig. 5 . It can be stated that the higher the level of forward primer, the higher the amplification products. 


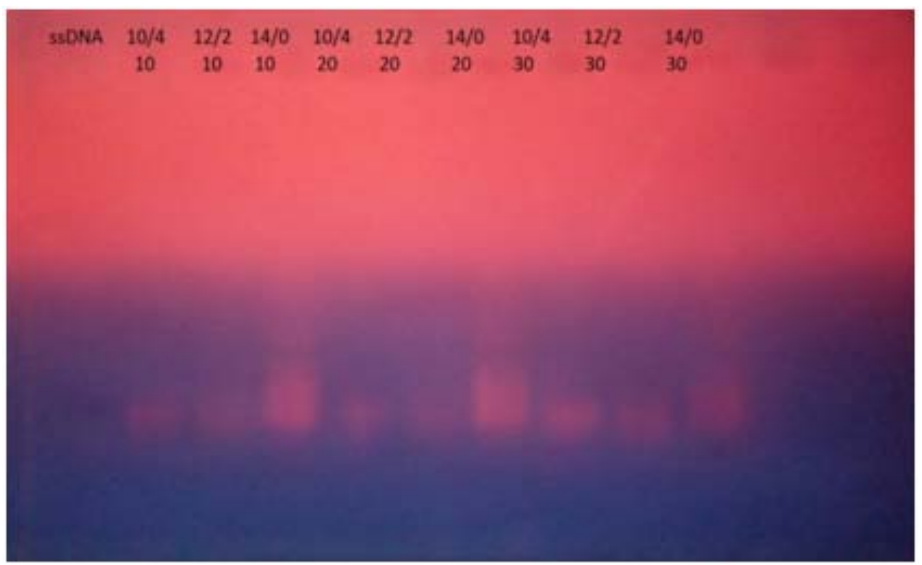

Fig. 4: The electrophoresis results of PCR amplification on gel agarose using asymmetrical PCR with primer ratios of 10/4, 12/2, and 14/0 from three different concentrations of ssDNA

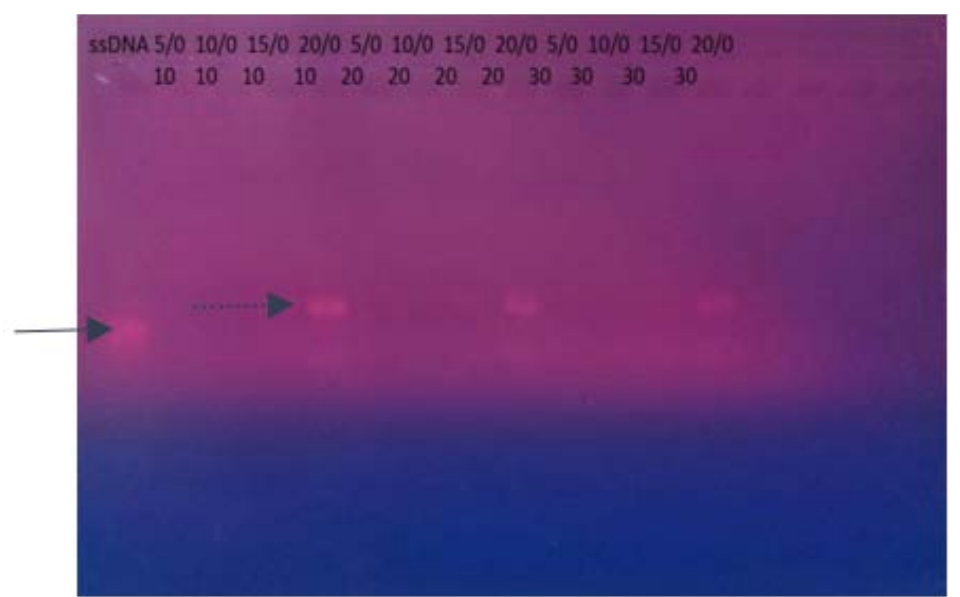

Fig. 5: The electrophoresis results of PCR amplification on gel agarose using asymmetrical PCR with primer ratios of 5/0, 10/0, 15/0, and 20/0 from three different concentrations of ssDNA, $(\longrightarrow)$ : ssDNA library; and $(\longrightarrow \rightarrow)$ ): ssDNA target of porcine gelatin from selection

During purification of ssDNA, PCR product was precipitated until final volume of $20 \mathrm{uL}$ with absolute ethanol. The product was purified on $10 \%$ native polyacrylamide electrophoresis (PAGE), TBE buffer $(89$ mmol tris-Borat, 2 mmol EDTA, pH 8.3), and stained with $0.5 \mu \mathrm{g} / \mathrm{ml}$ ethidium bromide in $1 \mathrm{x}$ bufer TBE for 7 min. ssDNA was purified using crush and soak. Band containing ssDNA was cut using the sterile cutter and placed into Effendorf.
Gel was destroyed using a sterile pipette tip followed by addition of $400 \mu$ leluting buffer (1M Na-acetate; $0.01 \mathrm{M}$ EDTA). A sample was incubated at $37{ }^{\circ} \mathrm{C}$ for $6-8 \mathrm{~h}$ with shaking at $900 \mathrm{rpm}$. Gel particles were precipitated using centrifugation at maximum speed for $2 \mathrm{~min}$. The supernatant was precipitated carefully using ethanol until the final volume of $20 \mu \mathrm{l}$. The results of PAGE $10 \%$ of ssDNA and DNA ladder were shown in fig. 6 .

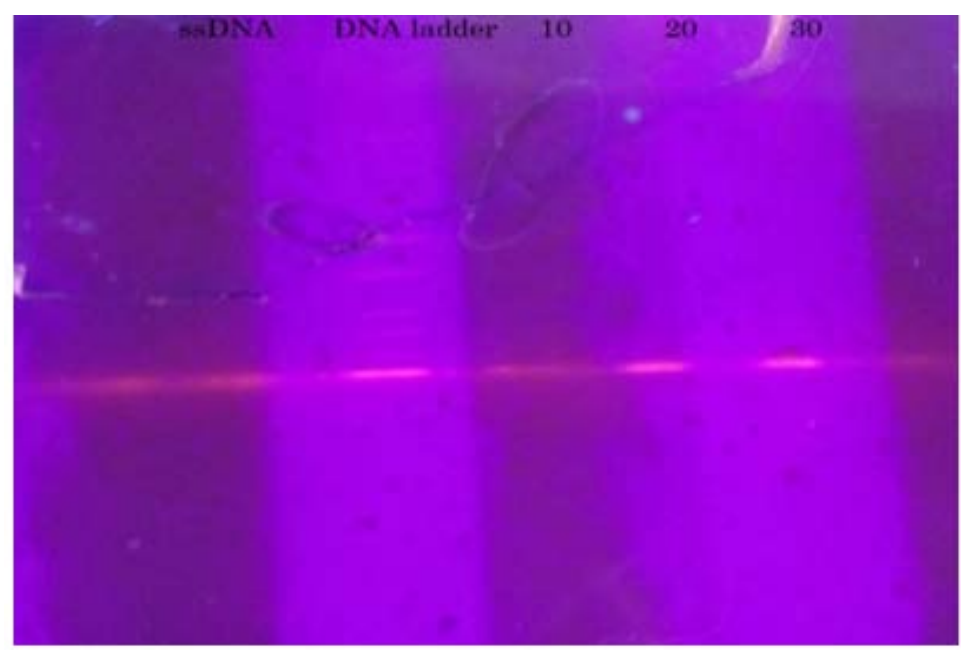

Fig. 6: The results of PAGE $10 \%$ of ssDNA, DNA ladder and samples with concentrations of 1,2 and 3 nmol 


\section{CONCLUSION}

Graphene oxide (GO) could be used to assist aptamer selection without immobilization process. The ability of GO could adsorb ssDNA specifically, not in dsDNA. In addition, the use of GO could assist the purification of selected aptamer because the residue of ssDNA which not bound to target (porcine gelatin) was bound into GO so that ssDNA target could be separated by centrifugation. Furthermore, the selected Aptamer can be used as a biosensor to detect porcine gelatin contamination for halal authentication purposes.

\section{ACKNOWLEDGMENTS}

The author thanks to the Ministry of research and higher education for financial support during this study through Penelitian Unggulan Perguruan Tinggi 2017-2018 awarded to Prof. Dr. Sismindari.

\section{AUTHORS CONTRIBUTIONS}

All the author have contributed equally

\section{CONFLICT OF INTERESTS}

The author declares that there is no conflict of interest

\section{REFERENCES}

1. Gibbs BF, Kermasha S, Alli I, Mulligan CN. Encapsulation in the food industry: a review. Int J Food Sci Nutr 1999;50:213-24.

2. Mondal N. The role of matrix tablet in drug delivery system. Int J Appl Pharm 2010;10:1-6.

3. Khatavkar UN, Kumar KJ, Shimpi SL. Novel approaches for the development of oral controlled release compositions of galantamine hydrobromide and paroxetine hydrochloride hemihydrate: a review. Int J Appl Pharm 2016;8:1-6.

4. Gomez Guillen MC, Perez Mateos M, Gomez Estaca J, Lopez Caballero E, Gimenez B, Montero P. Fish gelatin: a renewable material for the development of active biodegradable films. Trends Food Sci Technol 2009;20:3-16.

5. Ladislaus M, Kasankala YX, Weilong Y, Sun D, Hong Q. Optimization of gelatin extraction from grass carp (Catenopharyngodon idella) fish skin by response surface methodology. Biores Technol 2007;98:3338-43.

6. Murugaiah C, Noor ZM, Mastakim M, Bilung LM, Selamat J, Radu S. Meat species identification and Halal authentication analysis using mitochondrial DNA. Meat Sci 2014;83:57-61.

7. Hashim DM, Che Man YB, Norakasha R, Shuhaimi M, Salmah Y, Syahariza ZA. Potential use of fourier transform infrared spectroscopy for differentiation of bovine and porcine gelatins. Food Chem 2010;118:856-60.
8. Azilawati MI, Hashim DM, Jamilah B, Amin I. RP-HPLC method using 6-aminoquinolyl-N-hydroxysuccinimidyl carbamate incorporated with normalization technique in the principal component analysis to differentiate the bovine, porcine and fish gelatins. Food Chem 2015;172:368-76.

9. Zhang GF, Liu T, Wang Q, Chen L, Lei JD, Luo J, et al. Mass spectrometric detection of marker peptides in tryptic digests of gelatin: a new method to differentiate between bovine and porcine gelatin. Food Hydrocoll 2009;23:2001-7.

10. Rodriguez MA, Garcia T, Gonzalez I, Hernandez PE, Martin R. TaqMan real-time PCR for the detection and quantitation of pork in meat mixtures. Meat Sci 2005;70:113-20.

11. Chen SY, Liu YP, Yao YG. Species authentication of commercial beef jerky based on PCR-RFLP analysis of the mitochondrial 12S rRNA gene. J Genetics Genom 2010;37:763-9.

12. Ghovvati S, Nassiri MR, Mirhoseini S, Moussavi AH, Javadmanesh A. Fraud identification in industrial meat products by multiplex PCR assay. Food Control 2009;20:696-9.

13. Man YBC, Aida AA, Raha AR, Son R. Identification of pork derivatives in food products by species-specific polymerase chain reaction (PCR) for halal. Food Control 2007;18:885-9.

14. Tuerk C, Gold L. Sistematic evolution of ligands by exponential enrichment: RNA ligands to bacteriophage t4 DNA polymerase. Science 1990;249:505-10.

15. Kim YS, dan GuMB. Advances in aptamer screening and small molecule aptasensors. Adv Biochem Eng Biotechnol 2014;140:29-67.

16. Wang Y. Nitrogen-doped graphene and its application in electrochemical biosensing. ACS Nano 2010;4:1790-8.

17. Varghese N, Mogera U, Govindaraj A, Das A, Maiti PK, Sood AK, et al. Binding of DNA nucleobases and nucleosides with graphene. Chem Phys 2009;10:206-10.

18. Shabani H, Mehdizadeh M, Mousavi SM, Dezfouli EA, Solgi T, Khodaverdi M, et al. Halal authenticity of gelatin using speciesspecific PCR. Food Chem 2015;184:203-6.

19. Pfeiffer F, Mayer G. Selection and biosensor application of aptamers for small molecules. Front Chem 2016;4:1-25.

20. Citartan M, Tang TH, Tan SC, Hoe CH, Saini R, Tominaga J, Gopinath SCB. Asymmetric PCR for good quality ssDNA generation towards DNA aptamer production. Songklanakarin J Sci Technol 2012;34:125-31

21. Joeng CB, Niazi JH, Lee SJ, Gu MB. ssDNA aptamers that recognize diclofenac and 2-anilinophenylacetic acid. Biorg Med Chem 2009;17:5380-7.

22. Stoltenburg R, Reinemann C, Strehlitz B. SELEX-A (r) evolutionary method to generate high-affinity nucleic acid ligands. Biomol Eng 2007;24:381-403. 